\title{
THE ROLE OF CEREBRO-PONTO-CEREBELLAR PATHWAYS IN THE CONTROL OF VERGENCE EYE MOVEMENTS
}

\author{
PAUL D. R. GAMLIN, KYUNGHEE YOON and HONGYU ZHANG \\ Birmingham, Alabama
}

\begin{abstract}
SUMMARY
Single-unit recording and anatomical techniques have been used in Rhesus monkeys to investigate the central pathways involved in the neural control of vergence and ocular accommodation. Anatomical studies have revealed connections between the midbrain nearresponse region and the posterior interposed (IP) and fastigial nuclei of the cerebellum. Single-unit recording studies in the IP of alert, trained monkeys identified cells with activity that increased with increases in the amplitude of divergence and far accommodation, i.e. the far-response. Microstimulation at the site of these neurons often produced a far-response. Single-unit recording from a precerebellar nucleus, the nucleus reticularis tegmenti pontis (NRTP), identified some cells with activity that linearly increased with increases in the amplitude of the near-response, and some with activity that linearly increased with increases in the amplitude of the far-response. Microstimulation at the site of these near- or far-response neurons often produced changes in vergence angle and accommodation. Single-unit recording studies in the region of the frontal eye fields identified cells in the prearcuate cortex with activity that is modulated by either the near- or far-response. These results suggest that regions of the prearcuate cortex, the NRTP and the IP form part of a cerebro-ponto-cerebellar pathway modulating or controlling vergence and ocular accommodation.
\end{abstract}

Whenever eye movements are made between objects located at different distances, changes in vergence angle and accommodation are required. For example, when looking from a far to a near object, appropriate increases in convergence and accommodation ensure that the object is imaged on the fovea of each eye and is correctly focused. While the two

Correspondence to: Dr Paul Gamlin, Vision Science Research Center, 626 Worrell Building, University of Alabama at Birmingham, Birmingham, AL 35294, USA. Fax: +1 (205) 934 5725. major sensory drives for vergence and accommodation are disparity and blur, ${ }^{1-5}$ looming cues may also affect these eye movements. ${ }^{6,7}$ It has been known for many years that the vergence and accommodation systems are cross-coupled (see, for example, Fincham and Walton ${ }^{1}$ and Müller ${ }^{8}$ ), but this crosscoupling was first clearly described in its current form by Westheimer. ${ }^{9}$ A simplified version of a recent cross-coupled model of vergence and accommodation is shown in Fig. $1 .{ }^{10}$ When disparity is open-loop, blur-driven accommodation elicits convergence. When blur is open-loop, disparity-driven convergence elicits accommodation. Also, to account for the observation that vergence and accommodation show tonic adaptation (see, for example, Schor ${ }^{10}$ and Morley et al. $\left.{ }^{11}\right)$, the model incorporates slow neural integrators as well as fast neural integrators.

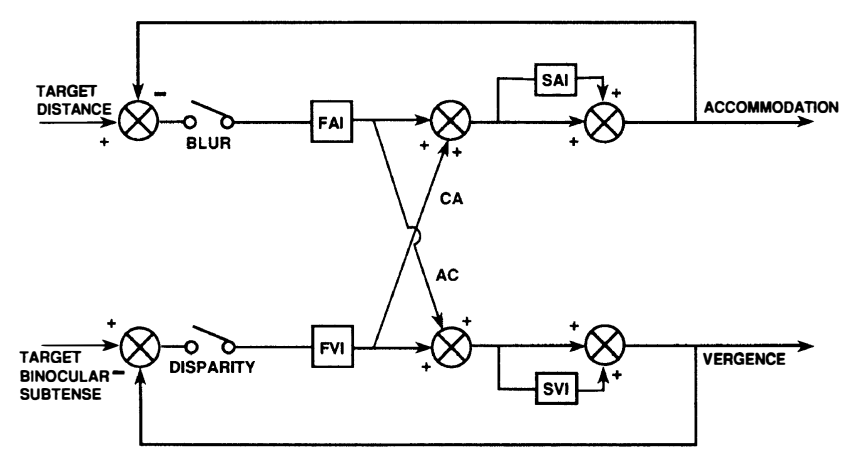

Fig. 1. A current model of the proposed cross-coupling between the vergence and accommodation systems. When disparity is open-loop (equivalent to opening the lower switch), blur-driven accommodation elicits convergence; this is known as accommodative convergence and is represented by $A C$. When blur is open-loop (equivalent to opening the upper switch), disparity-driven convergence elicits accommodation; this is known as convergence accommodation and is represented by CA. FAI, fast accommodation integrator; FVI, fast vergence integrator; SAI, slow accommodation integrator; SVI, slow vergence integrator. 
A

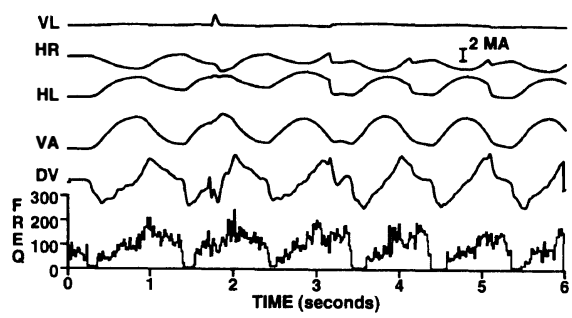

B

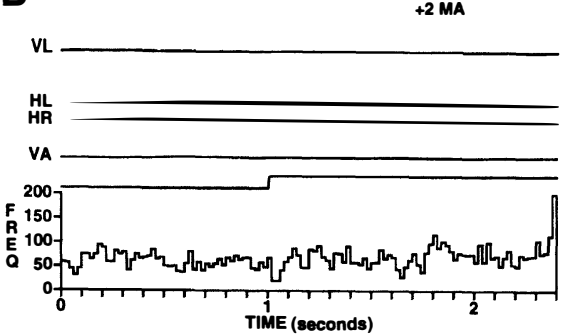

C

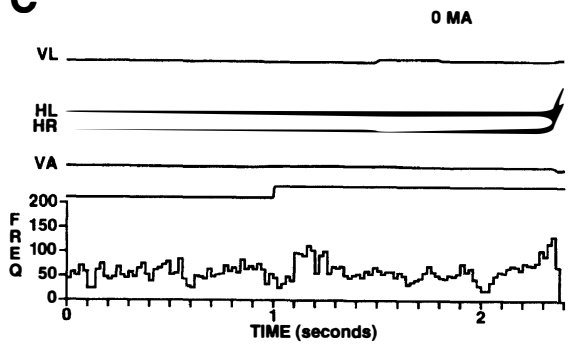

D -2 mA

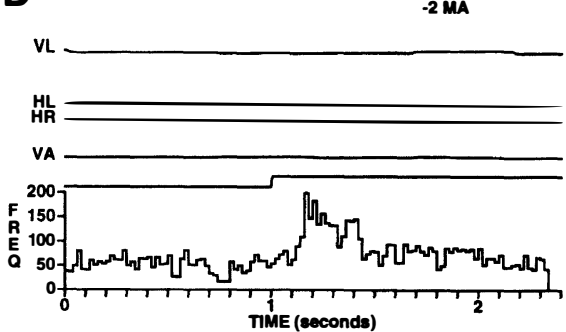

Fig. 2. The behaviour of a far-response cell in the posterior interposed nucleus (IP). Panel A shows that the activity of this cell is modulated during sine wave tracking of a target moving in depth. Panels $B-D$ show the behaviour of this cell in response to a target with different disparity and blur demands. During these trials, the animal is required to look to the target only after the fixation light is extinguished. Thus there is a period time, which is under experimental control, where the target is illuminated and the animal is required not to look away from the initial fixation target. The randomly timed target appearance, indicated by the step in the lowest trace, has been aligned to 1 second in all trials to facilitate comparison. In this example, $+2 M A$ is approximately equivalent to $a+4^{\circ}$ and +2 dioptre demand, while $-2 M A$ is approximately equivalent to $a-4^{\circ}$ and -2 dioptre demand. $D V$, divergence velocity; HL, horizontal left eye position; $H R$, horizontal right eye position; $V A$, vergence angle; $V L$, vertical left eye position.

Over the past few years, we have acquired extensive knowledge of the behavioural characteristics of vergence and accommodation and their interactions, ${ }^{1-5,10,11}$ but have only limited knowledge of the neural bases of these eye movements. Most studies of the neural control of vergence and ocular accommodation have concentrated on the behaviour of either the motoneurons for vergence eye movements, ${ }^{12-16}$ or the premotor neurons found around the oculomotor nucleus in the supraoculomotor area and adjacent reticular formation. ${ }^{11,17-21}$ This report reviews our recent efforts to describe more fully the central neural pathways involved in the control of vergence and accommodation.

The studies described below used alert, trained, juvenile Rhesus macaque monkeys (Macaca mulatta). All procedures were approved by the IACUC, complied with the USPHS Policy on Humane Care and Use of Laboratory Animals, and have been described previously.22,23 The optical system used in these studies was a binocular visual stimulator similar to one used previously by us $^{22}$ and based on the original design of Crane and Clark. ${ }^{24}$ However, it was modified to allow video displays to be used for target presentation, with each having its own independent accommodative and vergence demand.

\section{ROLE OF THE CEREBELLUM IN VERGENCE AND ACCOMMODATION}

The supraoculomotor area and adjacent reticular formation around the oculomotor nucleus contain premotor neurons for vergence and ocular accommodation. ${ }^{17-21}$ We have carried out anatomical studies to investigate the inputs to this region, and have found connections between it and specific deep cerebellar nuclei. ${ }^{25}$ Injections of wheat germ agglutinin/horseradish peroxidase (WGA-HRP) were placed under physiological guidance into this midbrain region. These injections resulted in retrogradely labelled cells in the deep cerebellular nuclei that were predominantly confined to the posterior interposed nucleus (IP) and the fastigial nucleus. We subsequently injected WGA-HRP into these deep cerebellar nuclei to use the anterograde capabilities of this tracer to define their midbrain projections. Injections of IP resulted in labelled terminals in the supraoculomotor area but not in the EdingerWestphal nucleus. Fastigial nucleus injections resulted in labelled terminals in a band along the 
border between the oculomotor nucleus and the supraoculomotor area that included the EdingerWestphal nucleus. These anatomical experiments thus revealed a clear pattern of connections that could underlie the cerebellar modulation of vergence and accommodation.

We therefore undertook single-unit recording studies of one of the identified deep cerebellar nuclei, the posterior interposed nucleus. These studies revealed tonically active cells in a localised region of the IP whose activity was modulated as a function of the velocity of divergence and far accommodation, i.e. the dynamics of the farresponse. $^{26,27}$ In addition, most cells encountered displayed a tonic firing rate that decreased as a function of near viewing. The activity of some of these IP neurons was tested during normal viewing, disparity vergence (blur open-loop) and accommodative vergence (disparity open-loop). In all cases, firing rate was modulated under all viewing conditions. Therefore, these cells would be expected to be located after the cross-links that couple blur and disparity to vergence and accommodation. Microstimulation in this region of IP produced divergence eye movements and matching decreases in accommodation, i.e. a far-response region. These studies suggested that this region of IP is involved in the control of the far-response, possibly by way of its projection to the midbrain near-response region.

In addition to their motor responses, some cells in this region of IP also display an apparent sensory component. ${ }^{27}$ An example of one of these cells is shown in Fig. 2. Panel A of this figure shows the behaviour of this cell during sine-wave tracking of a target moving in depth. Under this condition, the firing rate of the cell is closely related to divergence velocity (DV). In addition, panels $B-D$ show the apparent sensory component of this cell during delayed movement trials. With the appearance of a far target in panel $\mathrm{D}$, the cell shows a significant, transient increase in its activity that is not seen with the appearance of the near target in panel $\mathrm{B}$.

Although some previous studies in cats have reported positive accommodation with stimulation of this region of the deep cerebellar nuclei, ${ }^{28,29}$ the accommodation reported was extremely small, and indeed Westheimer and Blair ${ }^{30}$ questioned whether, in primates, the cerebellum played any role in vergence eye movements. Therefore our findings represent the most conclusive evidence to date for a role of the cerebellum in controlling vergence and accommodation. Our findings are also consistent with some recent clinical findings that have reported deficits in convergence with lesions of the cerebellar peduncles, ${ }^{31}$ and deficits in accommodation for far with a cerebellar lesion. ${ }^{32}$
A

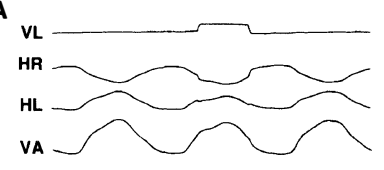

B
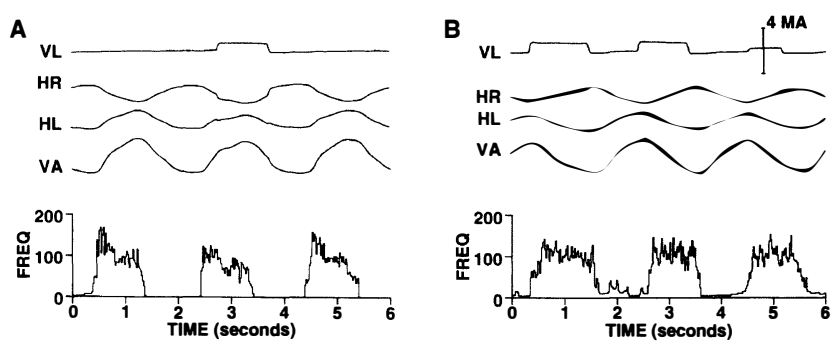

Fig. 3. Panel A shows the behaviour of a near-response cell in the nucleus reticularis tegmenti pontis (NRTP) during sine wave tracking in depth. Panel B shows the behaviour of a far-response cell in NRPT during sine wave tracking in depth.

\section{ROLE OF THE NRTP IN VERGENCE AND ACCOMMODATION}

Given the activity related to the far-response that was recorded from neurons of the IP, we decided to identify those precerebellar nuclei that might be providing the input to this nucleus. Single-unit recording from one precerebellar nucleus, the nucleus reticularis tegmenti pontis (NRTP), identified some cells that were related to convergence and some to divergence. ${ }^{23}$ The convergence-related neurons exhibited transient increases in their firing rate during the near-response. Many of these cells also had a tonic firing rate that increased as a function of increases in convergence and accommodation. An example of one of these cells is shown in Fig. 3A. Approximately equal numbers of cells were also encountered in the NRTP that showed transient increases in activity during divergence. In addition, many of these cells displayed tonic activity which declined to zero with increases in vergence angle of between 1 and 3 metre angles. An example of one of these cells is shown in Fig. 3B.

We found that many of these recorded cells were close to neurons displaying saccade-related activity, and marking lesions confirmed that the recording sites were in the medial NRTP in a location similar to that reported for saccade-related neurons. ${ }^{33}$

The activity of many of these NRTP neurons was tested during normal viewing, disparity vergence (blur open-loop) and accommodative vergence (disparity open-loop). In all cases, firing rate was modulated under all viewing conditions. Therefore, just as in the case of neurons in IP, these cells would be expected to be located after the cross-links that couple blur and disparity to vergence and accommodation.

Since the NRTP is known to receive cortical afferents and to have reciprocal connections with the cerebellum, we suggested that some cells in the medial NRTP could form part of a cerebro-cerebellar pathway modulating or controlling vergence and accommodation. ${ }^{23}$ This suggestion is supported by the recent single-unit recording studies in the 

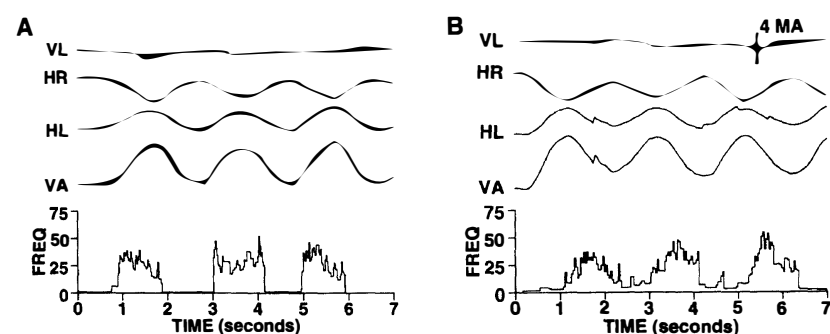

Fig. 4. Panel $A$ shows the behaviour of a near-response cell in prearcuate cortex during sine wave tracking in depth. Panel $B$ shows the behaviour of a far-response cell in the prearcaute cortex during sine wave tracking in depth.

prearcuate cortex of the Rhesus monkey described below.

\section{ROLE OF PREFRONTAL CORTEX IN VERGENCE AND ACCOMMODATION}

A few studies of cerebral cortex have reported cells in the parietal cortex that could be related to vergence and accommodation (see, for example, Sakata et al., ${ }^{34}$ Colby et al., ${ }^{35,36}$ and Gnadt and Mays $^{37}$ ). Also, stimulation in frontal cortex has been reported to produce disconjugate eye movements in anaesthetised monkeys. ${ }^{38}$ However, there have been no definitive studies of the cortical areas involved in vergence and accommodation. The region of the NRTP that contains near- and far-response related neurons ${ }^{23}$ receives a significant cortical input from area 8 of the frontal cortex,,$^{39-41}$ and a weaker input from the supplementary eye fields. ${ }^{42}$ We have therefore begun to study the activity of neurons in area 8 during vergence and ocular accommodation. ${ }^{43}$

Single-unit recording from area 8 in the prearcuate cortex identified neurons that showed activity specifically linked to the near-response or to the farresponse. The activity of a near-response neuron is shown in Fig. 4A, while that of a far-response neuron is shown in Fig. 4B. While most of these cells exhibit transient increases in their firing rate during these eye movements, some also display a tonic firing rate that is related to vergence angle and accommodation.

The region of area 8 related to saccadic eye movements includes the anterior bank of the arcuate sulcus and the immediate prearcuate cortex. ${ }^{44}$ The region involved in smooth pursuit eye movements includes the fundus of the arcuate sulcus. ${ }^{45,46}$ These regions have been termed collectively the frontal eye field (FEF). The present study suggests that the FEF may be involved in all voluntary eye movements, and that it may extend anteriorly to include a region of area 8 related to vergence and ocular accommodation.

\section{CONCLUSIONS}

Our studies have provided evidence for a cerebroponto-cerebellar pathway involved in the neural control of vergence and ocular accommodation.

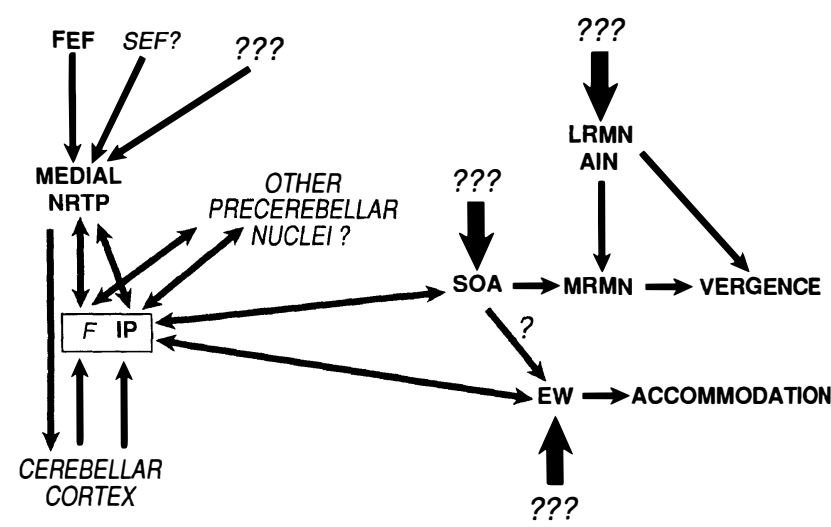

Fig. 5. This diagram summarises (in bold letters) the underlying connections that we and others have identified as being important in the neural control of vergence and ocular accommodation. The diagram also serves to identify those areas (italicised) that, on the basis of anatomical studies, appear to contain cells related to vergence and accommodation, or those areas (indicated by ???) that remain to be identified. MRMN, medial rectus motoneurons; LRMN, lateral rectus motoneurons; AIN, abducens internuclear neurons; EW, nucleus of Edinger-Westphal; SOA, supraoculomotor area; IP, posterior interposed nucleus; $F$, fastigial nucleus; NRTP, nucleus reticularis tegmenti pontis; $F E F$, frontal eye fields; SEF, supplementary eye fields.

This pathway is summarised in Fig. 5. To provide as complete a description as possible of our current knowledge of the central neural control of vergence and accommodation, those additional pathways that have been described electrophysiologically, ${ }^{47,48}$ or are suggested on the basis of anatomical studies, ${ }^{25,39-42}$ are also identified in Fig. 5.

We thank Steveanna Mason, Kelley Mitchell and Eric Eichman for technical assistance, and Sam Hayley and Chandrasekaran Venkatapathy for computer programming. This research was supported by NEI grant R01 EY07558 to P.D.R.G. and by NEI CORE grant P30 EY03039 .

Key words: Accommodation, Cerebellum, Convergence, Cortex, Divergence, Pontine nuclei.

\section{REFERENCES}

1. Fincham EF, Walton J. The reciprocal actions of accommodation and vergence. $\mathrm{J}$ Physiol (Lond) 1957;137:488-508.

2. Rashbass C, Westheimer G. Disjunctive eye movements. J Physiol (Lond) 1961;159:339-60.

3. Krishnan VV, Phillips S, Stark LA. Frequency analysis of accommodation, accommodative vergence, and disparity vergence. Vision Res 1973;13:1545-54.

4. Krishnan VV, Stark L. A heuristic model for the human vergence eye movement system. IEEE Trans Biomed 1977;24:44-9.

5. Hung GK, Semmlow JL. Static behavior of accommodation and vergence: computer simulation of an interactive dual-feedback system. IEEE Trans Biomed Eng 1980;29:439-47.

6. Kruger PB, Pola J. Changing target size is a stimulus for accommodation. J Opt Soc Am 1985;2:1832-5.

7. McLin L, Schor CM, Kruger P. Changing size 
(looming) as a stimulus to accommodation and vergence. Vision Res 1988;28:883-93.

8. Müller J. Elements of physiology, transl Baly W. London: Taylor and Walton, 1843.

9. Westheimer G. Amphetamine, barbiturates and accommodative convergence. Arch Ophthalmol 1963; 70:830-6.

10. Schor CM. A dynamic model of cross-coupling between accommodation and convergence: simulations of step and frequency responses. Optom Vis Sci 1992;69:258-69.

11. Morley JW, Judge SJ, Lindsey JW. Role of monkey midbrain near-response neurons in phoria adaptation. J Neurophysiol 1992;67:1475-92.

12. Robinson DA. Oculomotor unit behavior in the monkey. J Neurophysiol 1970;33:393-404.

13. Schiller $\mathrm{PH}$. The discharge characteristics of single units in the oculomotor and abducens nuclei of the unanesthetised monkey. Exp Brain Res 1970;10: 347-62.

14. Keller EL. Accommodative vergence in the alert monkey: motor unit analysis. Vision Res 1973;13: 1565-75

15. Mays LE, Porter JD. Neural control of vergence eye movements: activity of abducens and oculomotor neurons. J Neurophysiol 1984;52:743-61.

16. Gamlin PDR, Mays LE. Dynamic properties of medial rectus motoneurons during vergence eye movements. J Neurophysiol 1992;67:64-74.

17. Mays LE. Neural control of vergence eye movements: convergence and divergence neurons in the midbrain. $\mathrm{J}$ Neurophysiol 1984;51:1091-108.

18. Mays LE, Porter JD, Gamlin PDR, Tello CA. Neural control of vergence eye movements: neurons encoding vergence velocity. J Neurophysiol 1986;56:1007-21.

19. Judge SJ, Cumming BG. Neurons in the monkey midbrain with activity related to vergence eye movement and accommodation. J Neurophysiol 1986;55: 915-30.

20. Zhang Y, Gamlin PDR, Mays LE. Antidromic identification of midbrain near response cells projecting to the oculomotor nucleus. Exp Brain Res 1991;84:525-8.

21. Zhang Y, Mays LE, Gamlin PDR. Characteristics of near response cells projecting to the oculomotor nucleus. J Neurophysiol 1992;67:944-60.

22. Gamlin PDR, Gnadt JW, Mays LE. Lidocaine-induced unilateral internuclear ophthalmoplegia: effects on convergence and conjugate eye movements. J Neurophysiol 1989;62:82-95.

23. Gamlin PDR, Clarke RJ. Single-unit activity in the nucleus reticularis tegmenti pontis related to vergence and ocular accommodation. J Neurophysiol 1995;73: 2115-9.

24. Crane HD, Clark MR. Three-dimensional visual stimulus deflector. Appl Optics 1978;17:706-14.

25. May PJ, Porter JD, Gamlin PDR. Interconnections between the cerebellum and midbrain near response regions. J Comp Neurol 1992;315:98-116.

26. Gamlin PDR. Neural control of vergence and accommodation: a cerebellar 'far response' region. Invest Ophthalmol Vis Sci 1991;32:1125.

27. Zhang HY, Gamlin PDR. Sensorimotor characteristics of far response neurons in the cerebellum of the rhesus monkey. Invest Ophthalmol Vis Sci 1994;35:1282.

28. Hosoba M, Bando T, Tsukahara N. The cerebellar control of accommodation of the eye in the cat. Brain Res 1978;153:495-505.

29. Bando T, Ishihara A, Tsukahara N. The mode of cerebellar control of lens accommodation. In: Ito $\mathbf{M}$, Tsukahara N, Kubota K, Yogi K, editors. Integrative control functions of brain, vol 2. ??:??, 1980:149-50.

30. Westheimer G, Blair SM. Oculomotor defects in cerebellectomised monkeys. Invest Ophthalmol 1973; 12:618-20.

31. Ohtsuka K, Maekawa H, Sawa M. Convergence paralysis after lesions of the cerebellar peduncles. Ophthalmologica 1993;206:143-8.

32. Kawasaki T, Kiyosawa M, Fujino T, Tokoro T. Slow accommodation release with a cerebellar lesion. $\mathrm{Br} \mathrm{J}$ Ophthalmol 1993;77:678.

33. Crandall WF, Keller EL. Visual and oculomotor signals in nucleus reticularis tegmenti pontis in alert monkey. J Neurophysiol 1985;54:1326-45.

34. Sakata H, Shibutani H, Kawano K, Harrington TL. Neural mechanisms of space vision in the parietal association cortex of the monkey. Vision Res 1985;25:453-63.

35. Colby CL, Duhamel J-R, Goldberg ME. Ventral intraparietal area of the macaque: anatomic location and visual response properties. J Neurophysiol 1993;69:902-14.

36. Colby CL, Duhamel J-R, Goldberg ME. The analysis of visual space by the lateral intraparietal area of the monkey: the role of extraretinal signals. Prog Brain Res 1993;95:307-16.

37. Gnadt JW, Mays LE. Posterior parietal cortex, the oculomotor near response and spatial coding in 3-D space. J Neurophysiol 1995;73:280-97.

38. Jampel RS. Convergence, divergence, pupillary reactions and accommodation of the eyes from faradic stimulation of the macaque brain. J Comp Neurol 1960;115:371-400

39. Leichnetz GR, Smith DJ, Spencer RF. Cortical projections to the paramedian tegmental and basilar pons in the monkey. J Comp Neurol 1984;228:388-408.

40. Huerta MF, Krubitzer LH, Kaas JH. Frontal eye field as defined by intracortical microstimulation in squirrel monkeys, owl monkeys, and macaque monkeys. I. Subcortical connections. J Comp Neurol 1986;253: 415-39.

41. Stanton GB, Goldberg ME, Bruce CJ. Frontal eye field efferents in the macaque monkey. II. Topography of terminal fields in midbrain and pons. J Comp Neurol 1988;271:493-506.

42. Shook BL, Schlag-Rey M, Schlag J. Primate supplementary eye field. I. Comparative aspects of mesencephalic and pontine connections. J Comp Neurol 1990;301:618-42.

43. Gamlin PDR, Yoon K. Single-unit activity related to the near-response in area 8 of the primate frontal cortex. Soc Neurosci Abstr 1995;21:1918.

44. Bruce CJ, Goldberg ME. Primate frontal eye fields. I. Single neurons discharging before saccades. J Neurophysiol 1985;53:603-35.

45. Gottlieb JP, Bruce CJ, MacAvoy MG. Smooth eye movements elicited by microstimulation in the primate frontal eye field. J Neurophysiol 1993;69:786-99.

46. MacAvoy MG, Gottlieb JP, Bruce CJ. Smooth pursuit eye movement representation in the primate frontal eye field. Cerebral Cortex 1991;1:95-102.

47. Gamlin PDR, Gnadt JW, Mays LE. Abducens internuclear neurons carry an inappropriate signal for ocular convergence. J Neurophysiol 1989;62:70-81.

48. Gamlin PDR, Zhang Y, Clendaniel RA, Mays LE. Behaviour of identified Edinger-Westphal neurons during ocular accommodation. J Neurophysiol 1994; $72: 2368-82$. 